\title{
QUALITAT DEL SERVEI I SABOTATGE* DELS EMPLEATS: RELACIONS AMB LA SATISFACCIÓ I LES INTENCIONS DE COMPORTAMENT DELS CLIENTS
}

CALIDAD DE SERVICIO Y SABOTAJE* DE LOS EMPLEADOS: RELACIONES CON LA SATISFACCIÓN Y LAS INTENCIONES DE COMPORTAMIENTO DE LOS CLIENTES

SERVICE QUALITY AND EMPLOYEES' SABOTAGE*: RELATIONSHIPS WITH SATISFACTION AND CUSTOMERS' BEHAVIORAL INTENTIONS

\author{
Cristina Martínez Pérez, ${ }^{* *}$ Yolanda Estreder, ${ }^{* * *}$ \\ Esther Gracia, Vicente Martínez-Tur, Alice Maniezki****
}

DOI: 10.7203/anuari.psicologia.19.1.85

\begin{abstract}
Resum
En el present estudi s'analitzen les relacions de la qualitat de servei i dels comportaments de sabotatge dels empleats envers els clients, amb la satisfacció i les intencions de comportament de 90 clients d'una organització de serveis de la Comunitat Valenciana. Els resultats indiquen l'existència de diferents relacions entre les dues dimensions de qualitat de servei-funcional i relacional- i els comportaments de sabotatge dels empleats, per una banda, i les respostes dels usuaris -satisfacció, intencions positives envers l'organització i intenció negativa d'advertir a uns altres clients de la mala qualitat del
\end{abstract}

S'usa el terme «sabotatge», «sabotaje» i «sabotage» per definir les conductes a les quals es fa referència en el text de la investigació descrita i que es mesuren amb l'escala utilitzada (Wang et al., 2011).

** Facultat de Ciències Sociosanitàries - Universitat Miguel Hernández.

*** Institut Universitari d'Investigació en Psicologia dels Recursos Humans, del Desenvolupament Organitzacional i de la Qualitat de Vida Laboral (IDOCAL) - Universitat de València. Societat Valenciana de Psicologia. E-mail: <Yolanda.Estreder@uv.es>.

**** Institut Universitari d'Investigació en Psicologia dels Recursos Humans, del Desenvolupament Organitzacional i de la Qualitat de Vida Laboral (IDOCAL) - Universitat de València. 
servei-, per altra. Finalment es reflexiona sobre les implicacions d'aquesta investigació i es defineixen algunes línies futures d'investigació.

Paraules clau: qualitat del servei, comportaments de sabotatge, satisfacció, intencions positives, advertències.

\title{
Resumen
}

En el presente estudio se analizan las relaciones de la calidad de servicio $y$ de los comportamientos de sabotaje de los empleados hacia los clientes, con la satisfacción y las intenciones de comportamiento de 90 clientes de una organización de servicios de la Comunidad Valenciana. Los resultados indican la existencia de diferentes relaciones entre las dos dimensiones de calidad de servicio (funcional y relacional) y los comportamientos de sabotaje de los empleados, por un lado, y las respuestas de los usuarios (satisfacción, intenciones positivas hacia la organización e intención negativa de advertir a otros clientes sobre la mala calidad del servicio), por otra. Finalmente se reflexiona sobre las implicaciones de esta investigación y se definen algunas líneas futuras de investigación.

Palabras clave: calidad de servicio, comportamientos de sabotaje, satisfacción, intenciones positivas, advertencias.

\begin{abstract}
The present study analyzes the links from service quality and sabotage behaviors of the employees towards the customers to satisfaction and behavioral intentions of 90 clients of a service organization of the Valencian Community, Spain. The results indicated the existence of differential relationships between the two dimensions of service quality (functional and relational) and sabotage behavior of employees, on the one hand, and customer responses (satisfaction, positive intentions towards the organization and intention to warn other customers about the poor quality of the service), on the other. Finally we describe the implications of this research and define some future lines of research.
\end{abstract}

Key words: service quality, sabotage behaviors, positive intentions, warnings.

\section{Introducció}

Actualment, i en consideració dels elevats nivells de competitivitat en un món cada vegada més globalitzat, és important saber diferenciar-se i conéixer les variables més importants per assolir l'èxit mitjançant els empleats, és a dir, el capital humà (Chamorro i Tato, 2005). L'aportació dels empleats és especial- 
ment rellevant en el sector dels serveis, i cal tindre en compte la interacció directa amb l'usuari per tal de prestar els serveis (Adelli Estreder, 2008; Estreder i Adell, 2004; 2006). A Espanya, l'activitat en el sector serveis s'ha incrementat en gener d'enguanyaconseguint el major nivell desde fa set anys (González, 2017), per la qual cosa representa araaquest sector el $76 \%$ de l'activitat econòmica (INE, 2017). Resulta necessari, doncs, conéixer quines variables influiran en la satisfacció del client i en el seu comportament després de l'ús del servei (p. ex., Lee, Back, i Park, 2017). La qualitat de servei i els comportaments del treballador tenen, en aquest sentit, una influència molt significativa.

El concepte «qualitat» ha estat definit de diverses maneres, però, en referir-se a la qualitat de servei, es fa referència més concretament a la percepció delclienten relació amb la superioritato excel·lència del servei, on la interacció de l'empleat de contactei el client és summament important (Parasuraman, Zeithaml i Berry, 1985). Tradicionalment, l'estudi d'aquesta interacció s'havia centrat a mesurar el nivell d'assoliment de l'empleat en oferir el servei central o nuclear de l'organització d'una manera eficient. Amb posterioritat, Price, Arnould i Tierney (1995) indicaren la necessitat de considerar també el factor relacional o emocional en aquesta relació.

Així, en les investigacionsprèvies s'ha diferenciat entre qualitat funcional -eficiència amb què l'empleat presta el servei nuclear al client, amb èmfasi en aspectes instrumentals- iqualitat relacional -aspectes relacionals i emocionals de la interacció entre empleat i client, més enllà de la interacció habitual que l'empleat presta en el servei al client-, i es consoliden ambdues dimensions de qualitat, que se centren en el grau en què s'ha establit una relació positiva entre el treballador i el client (García-Buades, Martínez-Tur, Ortiz-Bonnín i Peiró, 2016; Sánchez-Hernández, Martínez-Tur, Peiró i Ramos, 2009). Així, la qualitat del servei oferida per un treballador no pot restringir-se sols a la prestació eficient del servei nuclear que està estipulat. També inclou altres aspectes que van més enllà, comara una atenció especial en termes relacionals o emocionals -p. ex., tracte autèntic al client-.

Altrament, diversos investigadors s'han focalitzat en els aspectes negatius del servei i han estudiat els comportaments negatius de sabotatge dels empleats - i. e., conducta intencionada de perjudicar- envers els clients (Wang, Liao, Zhan i Shi, 2011). Els estudis sobre sabotatge donen una perspectiva complementaria que enriqueixen l'estudi de la interacció entre empleat i client, ja que posen l'accent en una faceta negativa que no estava present a l'estudi de la qualitat de servei.

En relació als conseqüents de la qualitat de servei, destaca la satisfacció del client, definida com l'avaluació postús relacionada amb els sentiments positius associats a la selecció i ús del servei (Potočnik, Tordera, Martínez-Tur, Peiró i Ramos, 2011). Una altra variable important a considerar són les intencions de 
comportament (Zeithaml, Berry i Parasuraman, 1996), que fan esment a aspectes positius $-i$. e., intencions de tornar a fer ús del servei i de la seua recomanació a uns altres- i negatius -i. e., intencions d'advertir a uns altres de la mala qualitat del servei-. Aquesta diferenciació entre conseqüències positives i negatives de la interacció entre empleati client és fonamental perquè la investigació ha confirmat que els clients són més sensibles als aspectes negatius del servei que als positius (Martínez-Tur, Estreder, Moliner, Sánchez-Hernández i Peiró, 2016).

La diferenciació entre qualitat de servei funcional vs. relacional, d'una banda, i la consideració dels comportaments de sabotatge dels empleats envers els clients, per una altra, ha de permetre una predicció més precisa de la satisfacció i de les intencions de comportament dels clients. L'objectiu principal d'aquest estudi és el d'establir quines relacions diferenciades tenen les dimensions de qualitat de servei i el sabotatge amb les respostes de l'usuari. Més concretament, i donat que la qualitat de servei funcional -més instrumental-, la del relacional -més emocional-i el sabotatge -més focalitzat en els aspectes negatius de la relació de l'empleat amb el client- tenen una naturalesa diferent, és d'esperar que tinguen també unes relacions distintes amb les respostes de l'usuari. En el present estudi es vol comprovar si açò és així, per a la qual cosaes realitza un estudi empíric en un context real de prestació de serveis. Així es vol contribuir al coneixement establint quins són els principals predictors de les diferents respostes dels clients davant el comportament dels empleats en organitzacions de serveis.

Donada la naturalesa emocional de la qualitat de servei relacional, és d'esperar que aquesta dimensió de la qualitat tinga una relació de major magnitud amb la satisfacció del client, ja que la satisfacció en té també el component emocional. En canvi, la decisió de tornar a usar el servei i de recomanar-lo a altres té una funció instrumental que comparteix amb la qualitat funcional i, per tant, caldria esperar que aquestes intencions positives de comportament -tornar a usar el servei i recomanar a altres- tinguen una relació de major magnitud amb la qualitat de servei funcional. Finalment, les intencions de comportament negatives -advertir a altres possibles clients sobre la mala qualitat del serveihaurien de tindre una relació de major magnitud amb els comportaments també negatius dels treballadors. Si tenim en compte aquests arguments i la investigació revisats, es formulen les hipòtesis següents:

- Hipòtesi núm. 1. El constructe amb una relació de major magnitud amb la satisfacció del client serà la qualitat de servei relacional.

- Hipòtesi núm. 2. El constructe amb una relació de major magnitud amb les intencions positives de comportament -tornar a usar el servei i recomanar-lo a altres- serà la qualitat de servei funcional. 
- Hipòtesi núm. 3. El constructe amb una relació de major magnitud amb les intencions negatives de comportament -advertir sobre la mala qualitat del servei- serà el de comportaments de sabotatge dels empleats envers els clients.

\section{Metodologia}

El present és un treball empíric basat en un estudi de camp. S'ha utilitzat unametodologia correlacional, amb un disseny transversal per recollir les dades.

\section{Participants}

La mostra ha estat constituïda per un total de 90 clients. Entre aquests, hi ha una majoria d'homes, que en representen el 90\%. La mitjana d'edat és de 29.2 anys $(\mathrm{DT}=10.3)$. Es tracta d'una mostra de conveniència que no és representativa. No obstant això, s'ha seguit una aproximació de temps real (Stewart i Hull, 1992) que ha facilitat una alta taxa de resposta (95\%). Un dels membres de l'equip d'investigació va participar de manera directa en la recollida de dades, mitjançant la qual demanaven la participació mentre els clients feien ús del servei.

\section{Procediment}

El context seleccionat per dur a terme la present investigació ha estat integrat per tres salons de joc ubicats a la Comunitat Valenciana, que formaven part de la mateixa organització. Els clients d'aquests tipus de salesdisposen de servei de bar-cafeteria, màquines escurabutxaques, ruleta imàquines d'apostes esportives. Els qüestionaris van ser complimentats en diferents dies de la setmanai en horaris diversos perabastar a la major part dels perfils de clients d'aquest tipus d'establiment. Els clients van contestar els qüestionaris després d'haver fet apostes o després d'haver jugat a les màquines escurabutxaques. Per tant, tenien ja experiència amb el personal responsable de les màquines i de la cafeteria.

\section{Variables}

Les variables mesurades són la qualitat de servei funcional i relacional, els comportaments de sabotatge, la satisfacció i les intencions de comportament positives i negatives. S'han emprat escales consolidades en la investigació científica sobre les temàtiques que aborda aquest estudi. Quan ha sigut necessari, al- 
gun epígraf general s'ha adaptat per fer referència al context de serveis -salons de joc- on es va desenvolupar l'estudi:

Qualitat de servei funcional (4 ítems) i relacional (3 ítems) mesurat amb la versió reduïda de qualitat de servei validada per Molina, Moliner, MartínezTur, Cropanzano i Peiró (2015). L'escala de resposta és de tipus Likert amb 7 alternatives des de l'1 «Totalment en desacord» fins al 7 «Totalment d'acord». Un exemple d'ítem emprat en l'escala de qualitat de servei funcional és «Els serveis que presten els treballadors satisfan les necessitats dels clients» i en l'escala de qualitat de servei relacional és «Fan sentir als clients especials $\mathrm{i}$ importants».

Comportaments de sabotatge (5 ítems) mesurats amb l'escala de Wang i al., (2011), adaptada a la interacció cara a cara entre empleat i client. L'escala de resposta és de tipus Likert amb 5 alternatives des de l'1 «Totalment en desacord» fins al 5 «Totalment d'acord». Un exemple d'ítem és «El/els treballador/s m'han deixat a l'espera durant molt de temps intencionadament».

Satisfacció (3 ítems) mesurada amb la versió reduïda de satisfacció de tres ítems (Gottlieb, Grewal i Brown, 1994; Martínez-Tur, Peiró, Ramos, i Moliner, 2006) basada en l'instrument de mesura d'Oliver (1980). L'escala de resposta és de tipus Likert amb 5 alternatives des de l'1 «Totalment en desacord» fins al 5 «Totalment d'acord». Un exemple d'ítem és «Estic satisfet amb l'elecció d'aquest Saló».

Intencions de comportament positives ( 2 ítems) i negatives ( 1 ítem) mesurats amb l'escala de Peiró, Martínez-Tur i Ramos (2005). L'escala de resposta és de tipus Likert amb 5 alternatives des de 1'1 «Totalment en desacord» fins al 5 «Totalment d'acord». Un exemple d'ítem emprat en l'escala d'intencions positivesés «Si puc, tornaré a utilitzar aquest Saló de Joc en el futur» i en l'escala d'intencions negatives és «Advertiré a unes altres persones de la mala qualitat d'aquest Saló de Joc»r.

Variables control. Donat que nivell de qualitat en cada sala de joc pot ser diferent, així com el comportament dels empleats, considerem rellevant controlar el tipus de sala de joc. Com hi ha tres sales, hem creat dues variables dummy. Així mateix, controlem el sexe-variable dummy-i l'edat del client, ja que aquest tipus de variables sociodemogràfiques solen tindre un efecte sobre la qualitat de servei, la satisfacció del client i les seues intencions (SánchezHernández, Martínez-Tur, Peiró i Moliner, 2010).

\section{Anàlisi estadística}

L'anàlisi de regressió lineal és el mètode estadístic emprat per a estimar les hipòtesis formulades. En concret, són 3 les regressions que cal plantejar, una per cada variable criteri-satisfacció, intencions positives iadvertència-, i poste- 
riorment es consideren en un únic pas totes les variables predictores simultàniament: sexe, edat, sala de joc, qualitat servei funcional i relacional, i sabotatge.

\section{Resultats}

Els resultats descriptius es troben a la taula 1.En general, els clients tenen una opinió molt favorable del servei, amb valors mitjansen qualitat de servei funcional, relacional, satisfacció i intencions positives bastant alts. Contràriament, les mesures negatives -i. e., sabotatge iadvertència- mostren valors relativamentbaixos. La variable amb major dispersió és la qualitat de serveirelacional, i la de menor dispersió és la de sabotatge. Açò seria un indicatiu que els aspectes negatius del servei han estat valorats de forma molt semblant entre els participants en l'estudi, mentre que en l'escala de qualitatrelacionales troben puntuacions més dispars entre els enquestats.

TAULA 1

Estadistics descriptius $i$ correlacions

\begin{tabular}{|l|c|r|c|c|c|c|c|c|}
\hline & MITJANA & \multicolumn{1}{|c|}{ DT } & $\mathbf{1}$ & $\mathbf{2}$ & $\mathbf{3}$ & $\mathbf{4}$ & $\mathbf{5}$ & $\mathbf{6}$ \\
\hline 1. Qualitat funcional & 6.11 & .91 & $(.81)$ & & & & & \\
\hline 2. Qualitat relacional & 5.96 & 1.15 & $.65^{* *}$ & $(.82)$ & & & & \\
\hline 3. Satisfacció & 4.59 & .77 & $.46^{* *}$ & $.49 * *$ & $(.92)$ & & & \\
\hline 4. Intencions positives & 4.44 & .95 & $.56^{* *}$ & $.48^{* *}$ & $.65^{* *}$ & & & \\
\hline 5. Intenció negativa & 1.20 & .65 & $-.27^{* *}$ & $-.21^{*}$ & $-.33^{* *}$ & $-.26^{*}$ & & \\
\hline 6. Sabotatge & 1.19 & .47 & $-.22^{*}$ & $-.26^{*}$ & $-.29 * *$ & $-.25^{*}$ & $.71 * *$ & $(.81)$ \\
\hline
\end{tabular}

$\mathrm{DT}=$ Desviació Típica. Coeficients Alfa de Cronbach entre parèntesis. ${ }^{*} p<.05$

La qualitat de servei funcional del servei presenta una alta correlació positiva amb la qualitat relacional. La qualitat funcional també presenta correlacions positives amb les intencions de tornar a l'establiment i recomanar el servei a uns altres, mentre que són negatives en el cas de les advertències i els comportaments de sabotatge. La qualitat relacional presenta un patró de relacions molt similar a l'observat en el cas de la qualitat de servei funcional. Altrament, la variable de sabotatge per part dels empleats està positivament relacionada amb la intenció negativa d'advertència de la mala qualitat del servei. La correlació té una alta magnitud, indicant que si els clients valoren que el servei prestat pels treballadors és de sabotatge, augmenten significativament les seues reaccions negatives d'advertència a altres clients potencials. En canvi, les correlacions 
negatives del sabotatge amb la satisfacció i les intencions positives de repetir l'ús i recomanar a altres són de molta menor magnitud, encara que estadísticament significatives.

Els resultats deles anàlisis de regressió es mostren en les taules 2,3 i 4, i permeten precisar de manera més solida i clara el grau en què es confirmen les hipòtesis. En relació a la Hipòtesi 1 (taula 2), s'observa un únic efecte significatiu i positiu entre qualitat de servei relacional i satisfacció $(\mathrm{B}=.21, p<.01)$. Així, a major valoració de la qualitat de servei relacional major també el nivell de satisfacció informat pels clients. L'únic predictor significatiu és la qualitat de servei relacional, en consonància amb la Hipòtesi 1.

TAULA 2.

Regressió amb satisfacció com a variable depenent

\begin{tabular}{|l|c|c|}
\hline \multicolumn{3}{|c|}{ SATISFACCIÓ } \\
\hline & B & ET \\
\hline Sexe & .29 & .24 \\
\hline Edat.01 & .01 & \\
\hline Sala 1 - Dummy 1 & .19 & .17 \\
\hline Sala 2 - Dummy 2 & .20 & .25 \\
\hline Qualitat servei funcional & .20 & .10 \\
\hline Qualitat servei relacional & $.21 * *$ & .08 \\
\hline Sabotatge & -.26 & .16 \\
\hline \multicolumn{2}{|c|}{$.33^{* *}$} \\
\hline
\end{tabular}

Notes. ET $=$ Error Típic; $* * p<.01$

Els resultats també confirmen la Hipòtesi 2 (taula 3). De fet, l'única relació significativa és la de la qualitat de servei funcional i les intencions positives $(\mathrm{B}=.45, p<.01)$. La relació és positiva. Així, a major valoració de la qualitat de servei funcional major són també les intencions de tornar a utilitzar el servei i de recomanar-lo a uns altres potencials clients. 
TAULA 3

Regressió amb intencions positives com a variable depenent

\begin{tabular}{|l|c|c|}
\hline \multicolumn{3}{|c|}{ INTENCIONS POSITIVES } \\
\hline & B & ET \\
\hline Sexe & .13 & .29 \\
\hline Edat & -.01 & .01 \\
\hline Sala 1 - Dummy1 & .15 & .20 \\
\hline Sala 2 - Dummy 2 & -.12 & .30 \\
\hline Qualitat servei funcional & $.45^{* *}$ & .12 \\
\hline Qualitat servei relacional & .15 & .10 \\
\hline Sabotatge & -.25 & .19 \\
\hline \multicolumn{2}{|c|}{$.36^{* *}$} \\
\hline \multicolumn{2}{|c|}{$\mathrm{R}^{2}$} & \\
\hline
\end{tabular}

Notes. ET $=$ Error Típic; ${ }^{* *} p<.01$

Finalment, els resultats també confirmen la Hipòtesi 3 (taula 4), per ser els comportaments de sabotatge l'única variable que té una relació estadísticament significativa amb la intenció negativa d'advertència a uns altres $(\mathrm{B}=.97$, $p<.01)$. Així, quan els clients informen d'un major nombre de comportaments de sabotatge per part dels empleats, manifesten també una major intenció d'advertir a uns altres clients de la mala qualitat del servei.

TAULA 4

Regressió amb advertència com a variable depenent

\begin{tabular}{|l|c|c|}
\hline \multicolumn{3}{|c|}{ INTENCIÓ NEGATIVA (ADVERTÈNCIA) } \\
\hline & B & ET \\
\hline Sexe & -.21 & .16 \\
\hline Edat & .01 & .01 \\
\hline Sala 1 - Dummy 1 & -.14 & .12 \\
\hline Sala 2 - Dummy 2 & -.14 & .17 \\
\hline Qualitat servei funcional & -.13 & .07 \\
\hline Qualitat servei relacional & .03 & .06 \\
\hline Sabotatge & $.97 * *$ & .11 \\
\hline \multicolumn{2}{|c|}{$.55^{* *}$} \\
\hline
\end{tabular}

Notes. ET $=$ Error Típic; $* * p<.01$ 


\section{Discussió}

L'objectiu d'aquesta investigació s'ha centrat a estudiar les relacions entre les dimensions de qualitat de servei $-i$. e., funcional i relacional- i el comportament de sabotatge dels empleats, d'una banda, $i$ tres conseqüències valoratives dels clients en organitzacions de serveis -satisfacció, intencions positives i intencions negatives d'advertència-, d'altra.

Els resultats han donat suport a les hipòtesis plantejades. En la primera hipòtesi, ha predominat la qualitat de servei relacional en la predicció de la satisfacció del client. El factor emocional de les relacions entre client-empleat pren un paper essencial a l'hora de generar satisfacció en els clients i, conseqüentment, es crea una major vinculació afectiva del client envers l'organització. Cal indicar també que per a generar satisfacció ambels serveis, és summament important que el capital humà siga capaç d'aportar valor afegit en l'atenció al client, i no focalitzar-se únicament en la part funcional o instrumental del servei.

Tanmateix, en la segona de les hipòtesis es confirma que el caràcter més instrumental de la qualitat de servei, és a dir, el funcional on els clients valoren que el servei es porta a terme d'una manera eficient i ràpida per part dels empleats, augmenta la intenció de tornar-fidelitat-, així com la intenció de recomanar el servei a uns altres clients. Açò es podria entendre considerant que les intencions positives dels clients estan relacionades amb una presa de decisions -tornar o no-, en què també hi ha un caràcter instrumental, on es decideix si el servei ha proporcionat els beneficis per tornar - $\mathrm{o}$ no- a utilitzar-lo en el futur. Així doncs, encara que la dimensió relacional té la seua importància, no s'ha d'oblidar que els clients basen en bona mesura les seues decisions en aspectes instrumentals de l'atenció per part de l'empleat.

La tercera de les hipòtesis formulades també es confirma, en considerar la relació significativa entre les percepcions dels clients d'haver estat intencionadament mal atesos per part dels empleats -sabotatge- amb les intencions d'advertència a altres clients potencials. Identificar quina variable és capaç de predir les intencions d'advertir a altres clients sobre la mala qualitat del servei és especialment rellevant, perquè la investigació indica que les experiències negatives del servei són especialment perjudicials (p. ex., Martínez-Tur, i al., 2016).

Aquest estudi contribueix al coneixement establint quins són els principals predictors de les diferents respostes dels clients davant el comportament dels empleats en organitzacions de serveis. És ben sabut que el comportament dels clients és complex. Inclou aspectes funcionals o cognitius però també d'emocionals (Mano i Oliver, 1993). Així mateix, els aspectes positius han predominat en l'estudi de la qualitat de servei en la interacció empleat-client, però existeix un vessant negatiu per part de l'empleat que no és considerada per la investigació tradicional sobre qualitat de servei, i que té a veure ambels comportaments de 
sabotatge dirigits als clients (Wang et al., 2011). Identificar el millor predictor de cada tipus de resposta permet una comprensió més cabal del comportament del client en organitzacions de serveis.

Les variables relacionades amb aspectes emocionals estan estretament relacionades entre si. Quan els factors relacionals, com ara l'empatia, tractament especial ambels clients o oferir un tractament cordial i sincer són adequats, el factor emocional per part del client es troba afectat, i n'incrementa considerablement la seua satisfacció. Es pot afirmar, doncs, que els aspectes emocionals-relacionalsen l'encontre client-empleatajuden a estimular la satisfacció del client, és a dir, la seua vinculació afectiva amb l'organització. Altrament, les variables relatives a l'oferiment d'un servei eficient $\mathrm{i}$ ràpid -factors funcionals de la qualitat de servei- són importants per propiciar que els clients desitgen tornar a utilitzar el servei i que el recomanen també a uns altres. Així, la qualitat funcional percebudaes relaciona positivament amb les intencions positives dels clients envers l'establiment. En resum, l'adequada elecció del capital humà en les organitzacions és crucial per assegurarl'èxit del negoci, especialment en el sector servei, per la seua indubtable relació ambels clients tant en el vessant emocional com en la més funcional o instrumental. Per últim, és important crear una atmosfera en l'organització que evite els comportaments sabotatge, clau per les organitzacions, ja que fa possible que els clients en redueixen les intencions d'advertir a altres sobre la mala qualitat del servei, i açò resulta fonamental per a la viabilitat de les organitzacions.

Pel que fa a les implicacions pràctiques, una bona pràctica en recursos humans podria ser realitzar entrevistes per competències als candidats. Així es podrien detectar característiques en les persones com l'empatia o la seua orientació al servei. D'aquestamanera, es podria facilitar la predicció del comportament d'aquests empleats amb els clients. Altre suggeriment seria el fet de realitzar accions formatives i entrevistes individuals amb els empleats de forma periòdica, perconèixer els seus interessos en l'organització i els seus comportaments dirigits al client. Açò permet detectar, identificar i estimular aspectes positius. Així mateix, es poden corregir possibles problemesmitjançant accions que poden motivar als empleats a ser millors en el seu dia a dia i aportar valor afegit al servei, $i$ en conseqüència oferirien una millor qualitat de servei i evitarien conductes de sabotatge envers els clients.

Com passa amb tots els treballs d'investigació, aquest també té limitacions que convé tindre en compte per a futurs estudis. En destacaríem principalment. En primer lloc, el present estudi té un caràcter transversal, és a dir, només té un temps de mesura. En futurs treballs seria convenient afegir altres temps de mesuraaddicionals, amb un disseny longitudinal, la qual cosa permetrà arribar a conclusions més solides sobre les relacions proposades. En segon lloc, la investigació s'ha realitzat en un sector dels serveis molt concret: sales de joc. 
És veritat que aquest context comparteix característiques molt rellevants amb altres tipus d'organitzacions de serveis - p. ex., la interacció directa amb el treballador-. Tanmateix, seria convenient posar a prova si els resultats observats es troben també en altres tipus de serveis, és a dir, es poden generalitzar. Finalment, s'ha fet ús d'una mostra de conveniència. No obstant això, s'han recollit dades en diferents dies i horaris, i s'ha aconseguit tenir una alta taxa de resposta (95\%), per la qual cosa és raonable pensar que els diferents tipus de clients estan representats a l'estudi.

Malgrat aquestes limitacions, el present estudi fa una contribució rellevant al diagnosticar el principal predictor de diferents tipus de resposta del client en organitzacions de serveis: el comportament del client és complex. Té aspectes instrumentals però també emocionals. Pot apreciar l'esforç positiu de l'empleat en termes de qualitat de servei i tindre, d'altra banda, una resposta diferent enfront dels comportaments de sabotatge dels esmentats empleats. Aquesta investigació indaga en allò que permet prediu-re les diferents respostes del client, i en posa l'accent en la seua complexitat per tal d'arribar a una visió més cabdal.

\section{Referències}

Adell, M. A. i Estreder, V. (2008). La tutoria en ensenyament secundari. Anuari de Psicologia de la Societat Valenciana de Psicologia, 12(1), 101-118.

Chamorro, A. i Tato, J. L. (2005). Globalización y competitividad de las empresas: los recursos humanos. Análisis Económico, 20(43), 167-186.

Estreder, V. i Adell, M. A. (2004). Satisfacció i rendiment dels docents als centres educatius de la comunitat valenciana. Anuaride Psicologia de la Societat Valenciana de Psicologia, 10(2), 61-73. <http://roderic.uv.es/handle/ 10550/21656>.

Estreder, V. i Adell, M. A. (2006). El gènere, el tipus de contracte laboral i la titularitat dels centres, en relació amb la satisfacció laboral dels docents no universitaris. Anuari de Psicologia de la Societat Valenciana de Psicologia, 11(1), 49-66. <http://roderic.uv.es/handle/10550/21765>.

García-Buades, E.; Martínez-Tur, V.; Ortiz-Bonnín, S. i Peiró, J. M. (2016). Engaged teams deliver better service performance in innovation climates. $\mathrm{Eu}$ ropean Journal of Work and Organizational Psychology, 25(4), 597-612.

González, J. (2017). La industria y los serviciosimpulsan la actividad en el inicio del año. El País.

Gotlieb, J.; Grewal, D. i Brown, S. (1994). Consumer satisfaction and perceived quality: Complementary or divergent constructs? Journal of Applied Psychology, 79(6), 875-885. 
Instituto Nacional de Estadística [INE]. (2017). Indicadores del sector servicios del mercado.

Lee, A.; Back, K-J. i Park, J. (2017). Effects of customer personal characteristics on the satisfaction-loyaltylink: a multi-method approach. Service Business, 11(2), 279-297.

Mano, H. i Oliver, R. L. (1993). Assessing the dimensionality and structure of the consumption experience: Evaluation, feeling, and satisfaction. Journal of Consumer Research, 20(3), 451-466.

Martínez-Tur, V.; Estreder, Y.; Moliner, C.; Sánchez-Hernández, R. i Peiró, J. M. (2016). Under-over benefitting perceptions and evaluation of services. Journal of Service Theory and Practice, 26(4), 430-447.

Martínez-Tur, V.; Peiró, J. M.; Ramos, J. i Moliner, C. (2006). Justice perceptions as predictors of customer satisfaction: The impact of distributive, procedural, and interactional justice. Journal of Applied Social Psychology, $36(1), 100-119$.

Molina, A.; Moliner, C.; Martínez-Tur, V.; Cropanzano, R. i Peiró, J. M. (2015). Unit-level fairness and quality with in the health care industry: A justicequality model. European Journal of Work and Organizational Psychology, 24(4), 627-644.

Oliver, R. L. (1980). A cognitive model of the antecedents and consequences of satisfaction decisions. Journal of Marketing Research, 17(4), 460-469.

Parasuraman, A.; Zeithaml, V. A. i Berry, L. L. (1985). A conceptual model of service quality and its implications for future research. Journal of Marketing, 49(4), 41-50.

Peiró, J. M.; Martínez-Tur, V. i Ramos, J. (2005). Employees' overestimation of functional and relational service quality: A gap analysis. The Service Industries Journal, 25(6), 773-788.

Potočnik, K.; Tordera, N.; Martínez-Tur, V.; Peiró, J. M. i Ramos, J. (2011). Is service climat estrength beneficial or detrimental for service quality delivery? European Journal of Work and Organizational Psychology, 20(5), 681-699.

Price, L.; Arnould, E. i Tierney, P. (1995). Going to extremes: Managing services encounters and assessing provider performance. Journal of Marketing, 59(2), 83-97.

Sánchez-Hernández, R.; Martínez-Tur, V.; Peiró, J. M. i Ramos, J. (2009). Testing a hier archical and integrated model of quality in the service sector: Functional, relational, and tangible dimensions. Total Quality Management, 20(11), 1173-1188.

Sánchez-Hernández, R.; Martinez-Tur, V.; Peiró, J. M. i Moliner, C. (2010). Linking functional and relational service quality to customers' satisfaction and loyalty: differences between menand women. Psychological Reports, 106(2), 598-610. 
Stewart, W. P. i Hull, R. B. (1992). Satisfaction of what? Post hoc versus realtime construct validity. Leisure Science, 14(3), 195-209.

Wang, M.; Liao, H.; Zhan, Y. i Shi, J. (2011). Daily customer mistreatment and employee sabotageagainst customers: Examining emotionandre source perspectives. Academy of Management Journal, 54(2), 312-334.

Zeithaml, V. A.; Berry, L. L. i Parasuraman, A. (1996). The behavior alconsequences of service quality. Journal of Marketing, 60(2), pp. 31-46.

Data de recepció: $\quad$ 26-07-2017

Data d'acceptació: 07-01-2018 